\title{
«ТАМ, ЗА НИГДЕ, ЗА ЕГО ПРЕДЕЛОМ» (попытка диалога с философами)
}

Аннотация. Статья посвящена по-своему экстраординарному научному событию - появлению монографии, объединившей ведущих российских и зарубежных философов, которые впервые артикулировали многосторонний, подчас дискуссионный подход к трансдисциплинарности как проблеме, тенденции и методологическому принципу. Внимание уделено правам и возможностям мыследеятельности, пониманию науки в современном мире, философии - в науке, трансдисциплинарности - в философии. Внимание также обращено на актуализированные и обоснованные в монографии термины, понятия, концепты. Особое внимание уделено трансдисииплинарности в аспекте фундаментального и прикладного. В диалоге с авторами монографии обсуждается ряд вопросов, принципиально значимых для изучения и применения трансдисциплинарности. $K$ числу важных для автора относится перспективность для культурологии мыслей о сочетании в рамках трансдисциплинарности как научной, так и культурной составляющих. Сделаны выводы о том, что новизна проблем, решаемых 8 монографии, и само обращение к проблеме трансдисциплинарности раскрепощает философов, создаёт в книге атмосферу интеллектуальной свободы и дружеского взаимопонимания. Продуктивным для философского и культурологического знания мы считаем идею научного плюрализма, ответственного и тонкого обращения $c$ понятийным аппаратом (дискурс, парадигма, коммуникация, деятельность), предлагающего много своеобразных трактовок понятия «трансдисциплинарность» (идея целостности, концептуальное пространство).

Ключевые слова: трансдисциплинарность, философия, наука, методология, терминология, дискурс, парадигма, коммуникация, деятельность, целостность.

Abstract. This article is dedicated to the extraordinary scientific being - the emergence of the monograph that united the leading Russian and foreign philosophers, who were first to enunciate the multifaceted, at timed discussion approach towards interdisciplinarity as a problem, trend, and methodological principle. Attention is given to the rights and abilities of mental activity, understanding of science in the modern world, philosophy - in science, as well as interdisciplinarity - in philosophy. The author also focuses attention on interdisciplinarity in the fundamental and applied aspects. In dialogue with the authors of the monograph, a number of principally important questions for study and implementation of interdisciplinarity is being discussed. The conclusion is made that the novelty of the problems solved in the monograph, and the reference to the problem of interdisciplinarity itself, empowers the philosophers, creates the atmosphere of intellectual freedom and friendly mutual understanding in the book. Productive for the philosophical and culturological knowledge we consider the idea of scientific pluralism, responsible and delicate treatment of the conceptual apparatus (discourse, paradigm, communication, activity), which suggests multiple original interpretations of the notion "interdisciplinarity" (the idea of integrity, conceptual space).

Key words: Integrity, Activity, Communication, Paradigm, Discourse, Terminology, Methodology, Science, Philosophy, Interdisciplinarity.

Рецензия на книгу: Трансдисциплинарность в философии и науке: подходы, проблемы, перспективы / Под ред. В.А. Бажанова, Р.В. Штольца. М.: Изд. дом «Навигатор», 2015. 564 с.

Философский трактат - жанр утраченный, возвышенно-удалённый в историко-культурную ре- троспективу. Сочинение, имеющее одного автора и обозначенное как «диссертация», либо статья, жанр привычный в современной научной жизни. Как и сборник статей, соединённых по принципу служебной близости авторов либо их участия в каком-либо научном мероприятии. В контексте таких изданий или не изданных, но публично пред-

Выполнено по гранту Российского научного фонда № 14-18-01833

«Текст и контекст массовой культуры: российский дискурс». 


\section{Философия и культура 4(100) • 2016}

ставленных текстов, появление коллективной философской монографии - уже событие нерядовое. Если же проблема, которой посвящена монография, не просто существует, но этим изданием по сути артикулируется как объективно существующая и способная претендовать на сугубое внимание к себе, - такое издание можно счесть событием экстраординарным. Это событие самими авторами, по всей видимости, воспринимается в горизонте мировой культурной традиции философствования, в силу чего (редкость!) каждая часть текста предваряется эпиграфами, взятыми из стихов великих поэтов-философов недавнего времени, И. Бродского и Н. Заболоцкого. Фразу И. Бродского и мы сочли возможным вынести в заголовок своего диалога.

В современном, глобальном, как уже принято постоянно напоминать, мире особенностью новой монографии стал интернациональный состав авторов, представляющих, кроме России, не только разные страны - Швейцарию, Францию, США, Нидерланды, Швецию, - но и учебные и научные заведения в количестве, большем, чем количество стран. Монография и вышла под двойной редакцией, русского философа науки В. Бажанова и швейцарского методолога науки Р. Шольца [1]; и поданы материалы в концептуально специфическом формате - по-русски с английскими аннотациями и ключевыми словами у русских авторов, поанглийски с русскими аннотациями и ключевыми словами - у авторов иностранных. Картина взаимодействия становится объёмной, убедительной и обнадеживающей. Полифоничность замысла и его воплощения предполагает готовность читателей к пониманию не только в общефилософском, но и в конкретном, лингвистическом смыслах. Русскому читателю, которому мы далее адресуем анализ русскоязычной составляющей монографии, должно быть интересно и важно увидеть аналогичные тенденции в работе авторов из разных стран. Одни, как Р. Шольц и его соавторы и коллеги по Цюриху, пишут, как принято говорить у нас, практикоориентированные тексты, учитывая, видимо, особо значимые для них образовательные интенции философов (мы уже можем работать с предложенным ими «трансдисциплинарным case studies» подходом, обозначенным аббревиатурой TCS [1, с. 32], с рассуждениями Шольца о роли университетов и академий в распространении грамотности, в первую речь идёт о грамотности «в отношении окружающей среды и устойчивого развития» [1, с. 366]). Р. Шольц и в своей единолично написанной работе проявляет специальное внимание «исследованию систем человек - среда», и здесь слышится своего рода призыв к целостности познания, к осущест- влению взаимодополнительности «материального и социального» [1, с. 180]. Другие, как, например, американка Дж.Т. Клейн, автор из Нидерландов М. Кеестра, автор из Швеции Хр. Пол и, особенно, всеми почитаемый и цитируемый парижский профессор Б. Николеску предпочитают работать в теоретическом, тезаурусно и методологически обрисованном поле.

Заметим попутно: монография обладает особой притягательностью взаимного человеческого общения авторов, объединившихся «под одной обложкой». Они действительно хорошо знают труды и интересы друг друга, много и, что называется, по делу ссылаются друг на друга. От этого при чтении без малого шестисотстраничного тома (книга к тому же издана в нестандартном формате, объём её даже физически внушителен) возникает ощущение тесного и давно сложившего общения единомышленников.

На всякий случай подчеркну то свойство монографии, которое может показаться читателю-неофиту странным, отчасти назойливым и необязательным. Каждый автор выражает своё отношение к междисциплинарности и трансдисциплинарности, почти каждый интерпретирует понятие «трансдисциплинарность». По ходу чтения это не сразу вызывает понимание, потом, напротив, - интерес: мы читаем философский детектив, где у каждого участника - своя версия происходящего поиска. Могу предположить, что для коллективной монографии это «упорство» не менее важно, чем для отдельного авторского материала: рождается многогранность, обеспечивающая концептуальное единство книги.

\section{1. Права и возможности мыследеятельности. Понимание науки - в мире, философии -} в науке, трансдисциплинарности - в философии

В монографии идёт речь о явлении, не таком уж редком в науке, особенно в последние два столетия: о возникновении и удовлетворении потребности в новых принципах, подходах, механизмах изучения, как только что возникших, так и издревле существующих, но нуждающихся в постоянном осмыслении явлений, феноменов, коллизий применительно к современности. Учёные, философы обсуждают «симбиотические формы» новых наук (В. Порус [1, с. 417]), видя в этом не только методологическую проблему, но уже стратегию науки. Это, впрочем, важное обстоятельство, характеризующее новую и уникальную масштабность проблем и составом авторов книге, не было бы достаточным основанием для нашего особого внимания к ней. Особое внимание обусловлено значимостью 
идей и способов их обсуждения для изучения той области, представление о которой в книге присутствует, хотя (к сожалению для нас) упоминается не очень часто; речь идёт о культуре и возможности её изучения с учётом высказанных и доказанных в монографии идей.

Именно в силу малочисленности обращения к сфере культуры - а к каким другим сферам обращаются авторы, мы скажем ниже, - факт и модальность этих обращений заслуживает специального внимания. Мы с особой благодарностью видим упоминания В. Поруса о связи между философией науки и философией культуры $[1$, с. 416] и о том, что новая стратегия науки «вписывается в стратегию внутреннего единства культуры» [1, c. 419], а трансдисциплинарность «нужно рассматривать как новый тип связи между наукой и культурой» [1, с. 428]. Мы полагаем характерным для философских трудов, но не столь уж часто встречающимся сегодня опыт использования литературного произведения (фантастического романа Р.Ф. Джоунса «Уровень шума») для демонстрации возможностей междисциплинарности в познании мира. Я. Свирский едва ли не радуется созданию в романе особой интеллектуальной атмосферы, которая характеризуется присутствием «не только научного истеблишмента» с присущими ему «дисциплинарными кодами», но и странного конгломерата персон, куда входят «культурологи, литераторы, мистики» [1, с. 237-238]. Не обсуждая странного, с нашей точки зрения, соединения в общем списке культурологов (учёных, теоретиков) с литераторами и мистиками (субъектами локальных культурных практик), отметим продуктивность и перспективность именно для культурологии мысли философа о сочетании в рамках трансдисциплинарности как научной, так и культурной составляющих (применительно к последним упоминается о религиозной, литературной, театрально-художественной, этической, политической составляющих [1, с. 243]).

В условиях подчас беглого, подчас агрессивнокатегоричного (не в данной монографии, но в научной практике в целом) обсуждения рамок, прав и возможностей отдельных наук, важной, пусть и мимоходом высказанной представляется оценочная реплика о дилетантизме и псевдонаучности, перед которыми философский анализ междисциплинарности может возвести барьер (В. Порус [1, c. 420]). Романтическая надежда, но - почему бы ей не осуществиться со временем?

В то же время авторы монографии, знающие о междисциплинарности больше многих наших современников и соотечественников, не подвержены соблазну огульного отрицания дисциплинарности, видя и её неоднозначность, и значение личностного модуса исследования (П. Тищенко [1, с. 476]). В условиях взыскующей действительности - «экзистенциальных проблем» - и расширения методологических рамок до трансдисциплинарного, трансакадемического и трансинституционального сдвигов, философ видит в трансдисциплинарности «место встречи для совместны усилий по разрешению экзистенциальных проблем реального мира» (П. Тищенко [1, с. 469]).

Монография показывает, а иногда и подчёркивает, что само обращение к проблеме трансдисциплинарности определённым образом раскрепощает философов, которые не только вежливо цитируют предшественников, но и дискутируют с ними либо дают возможность читателю вступить в полемику с ними самим. Так, размышления В. Бажанова о научной революции не только отсылают к известным идеям Т. Куна, но упоминанием об отрицаемом Куном «парадигмальном плюрализме» в сочетании с рассматриваемым самим В. Бажановым «трансдисциплинарным плюрализмом» позволяют читателю и заинтересоваться предложенной альтернативой, и согласиться с русским автором, видящим в последнем («трансдисциплинарном плюрализме»), как он пишет, «вполне естественное явление» [1, с. 140]. К сожалению, столь популярное ещё недавно в политической сфере понятие плюрализма слишком мало сегодня востребовано в научной мысли вообще, да и в настоящей монографии в частности; тем более ценно внимание к понятию и, разумеется, явлению, обозначающему право «сметь своё суждение иметь» для участника диалога, будь то дисциплинарно близкий или трансдисциплинарно удалённый исследователь.

В строгости научного издания присутствует заметная внимательному читателю атмосфера и даже подчас формулируется идея свободы: не анархии, разумеется, а права на выход за привычные рамки понимания и предметного анализа. Продолжая только что упомянутую линию «плюрализма», находим такие интенции и у В. Моисеева, обращающего внимание на «точки роста» научного знания через развитие «комплексного феномена транснауки» и пытающегося обозначить прогноз в столь эфемерной сфере, как наука [1, с. 170], и у В. Буданова, который об экстравагантном, с привычной точки зрения, говорит как об уже принятом и понятом - это касается суждений об «антропологическом сдвиге», они, в свою очередь, демонстрируют трансдисциплинарный подход к проблеме, уверенно, но не декларативно опровергая распространённые стенания относительно технократического 


\section{Философия и культура 4(100) • 2016}

характерна современной цивилизации [1, с. 157]. Неудивительно, что именно, как нам представляется, пребывая в атмосфере свободы научной мысли, исследователь позволяет себе высказывание, с одной стороны, естественное для философской традиции, что античной, что немецкой классической - о «рефлексии науки по поводу пересмотра своих идеалов, норм и ценностей, технологий научного познания и взаимодействия науки с обществом» [1, c. 147], с другой стороны - едва ли еретическое по отношению к дошедшей до наших дней образовательной традиции, требующей, изучить-отреферировать-сослаться-опереться-приобщиться, но не вторгаться в святая святых методологии с новыми вопросами и новыми объектами исследования. Вузовскому профессору, мне хочется в каждой учебной аудитории повесить плакат, где будет провозглашено «доминирование междисциплинарных и трансдисциплинарных мотивов в современной науке», подчеркнув столь нетривиально употребленное слово «мотив» (В. Буданов [1, с. 147]).

Продолжая рассматривать проявления свободы научных суждений и высказываний, мы отмечаем достаточно странную для обычных философских штудий, но естественную в контексте данной монографии рядоположенность формально главного и откровенно локального, привычно устоявшегося и принадлежащего только одному автору. Логично в монографии и её общей стилистике выглядит рассуждение Л. Киященко об эффекте «совместного коммуникативного трансдисциплинарного усилия (спора или обсуждения)», где явно имеется в виду не механизм, а - куда шире - интеллектуальная установка [1, с. 120]. Нас не удивляет, что Е. Князева, известная своими работами по синергетике, и в данной монографии особое внимание уделяет этой научной дисциплине, рассматривая присущую синергетике междисциплинарность как футурологический концепт [1, с. 291], а «кризис как путь к инновации» [1, с. 293]. Но наряду с этими, не удивительными в синергетической парадигме репликами и понятиями, автор как о само собой разумеющейся упоминает о «когнитивной науке» (cognitive science [1, c. 294]), что вызывает некоторое недоумение, поскольку наука, очевидно, не только совокупность методов, но и система осмысления некоторого предмета. В этом упоминании мы видим дань своего рода проявлению массового сознания в академическом исследовании, поскольку многие Internet-источники когнитивной наукой ничтоже сумняшеся называют всего-навсего комплекс наук (поэтому существует и другое, не употребленное здесь понятие «когнитивные науки», где присутствует механический перечень ряда так называемых социогуманитарных наук); иными словами, автор предлагает псевдоним - или метафору - трансдисциплинарности, упоминая к тому же и «биосемиотический подход», основанный на том, что «человек - символическое животное» [1, c. 298-299]. Но, повторяю, мы здесь не дискутируем, а лишь отмечаем выбранный авторами монографии тон свободных высказываний, сделанных подчас без детальных доказательств и логических ходов, в силу убеждения и имеющихся личных наработок и взглядов.

Наконец, упоминаемая нами свобода высказываний и, что её предваряет, свобода рассуждений о методологических проблемах выражается самым конкретным образом: метафорическими, индивидуально детерминированными определениями действий и приёмов работы. Именно так читаются и провоцируют стремление к диалогу и взаимопониманию реплики Г. Гутнера о привычных границах между наукой и «не-наукой», когда «пребывание за границей» принятой предметности формируется трансдисциплинарность исследования [1, с. 264]; так воспринимается достаточно спорное, но привлекательное и привлекающее к дискуссии - в которую мы сейчас не вступаем в силу лимитированного объёма собственного текста - высказывание П. Тищенко о разных и не всегда сопоставимых мирах, которые он противопоставляет друг другу: «серьёзного мира науки и производства» и мира, как следует понимать из контекста, несерьёзного - мира «праздничности», к нему категорично относится всё, что не принадлежит миру науки [1, с. 482]. И уж вовсе игровой характер приобретает высказывание о междисциплинарности в версии В. Поруса, употребляющего демонстративно масскультовское выражение и берущего его в кавычки: он называет междисциплинарность «бартерным рынком метафор и аналогий» $[1$, с. 424]. Впрочем, помимо свободы обращения с научными святынями в этой нарочито не академической по лексике реплике привлекает весьма продуктивная идея взаимообмена, впрочем, сформулированная внятно и броско, с намеком на спекулятивность и прагматизм интеллектуальной деятельности.

\section{2. Термины, понятия, концепты}

Обращение к понятию «трансдисциплинарность» (далее, для краткости, Т.) отнюдь не назначает для большей части авторов того, что проблема решена. Обсуждается не только генезис тенденции и содержание деятельности, но и сам терминологический аппарат. Обсуждается разносторонне, иногда поле- 
мически, иногда категорично, но это обсуждение даёт картину погружённости учёных в проблему и невозможности единого мнения о её содержании. Не случайно в одном из фрагментов монографии можно увидеть рассуждения о «транснауке», где в шести пунктах даётся обозначение особого взгляда на методологический феномен, явно более обширный и значимый чем обсуждаемая конкретная проблема Т. (В. Моисеев [1, с. 160]).

Для одних авторов Т. - больше, чем механизм или парадигма, это - идея, в частности, идея целостности (Л. Киященко [1, с. 116-117]); однако такое широкое понимание Т. не исключает казусов «жизненно-практических ситуаций» (Л. Киященко [1, с. 133]). Иными словами, теоретическая всеохватность и привязка к действительности воспринимаются как органические признаки бытования Т.

Для других авторов (В. Бажанов [1, с. 138-139], вслед за Е. Князевой и Т. Куном) Т. - это «стиль мышления», основанный на использовании когнитивных схем и осуществляющий «экспансию в широкое пространство культуры» из сферы какойлибо одной дисциплины.

Для третьих авторов Т. - своего рода медиатор, позволяющий осуществить переход от означаемого, каким учёный (П. Тищенко [1, с. 471]) видит Т., к означаемому - экзистенциальным проблемам, нуждающимся в «одомашнивании», преобразовании хаоса в порядок.

Для четвёртых Т. - как это следует из текста, хотя, возможно, автор и не имел в виду такое буквальное толкование, - это синоним «транснауки» (В. Моисеев [1, с. 160]) «как новой стадии развития методологии». Причём этот автор, как и многие другие в настоящем издании, настойчиво подчёркивает принципиальное и, скорее всего, не вызывающее уже возражений различие меж- и трансдисциплинарности [1, с. 165-166].

Для пятых Т. - это вроде бы уже и не наука, и не научная дисциплина, и не парадигма, а ещё больше - «концептуальное пространство», связывающее между собой рад понятий, а также то, что можно именовать «сложностью мира» (Я. Свирский [1, c. 236]). Нельзя не заметить, что новизна обсуждаемой научной проблемы в основном не приводит авторов к попытке разрушения традиционных философских способов выражения мыслей, в силу чего та же Т. характеризуется через ряд других понятий (дивергенция, коэволюция, ризома и т.п.), сам набор и состав которых хоть и принадлежит новейшему научному времени, но спокойно сочетается как с традиционными и фундаментальными (бытие), так и с более поздними, но уже вжившимися с научную лексику (становление). Отметим в этой связи появление парадоксальных словосочетаний, удивляющих уже не раз упоминавшейся свободой и естественностью использования прежде устоявшихся понятий в их новой связи. Таково сочетание понятий «казус» и «концепт» (Л. Киященко [1, c. 112, 115]), когда первый коррелируется с парадоксом, второй с возможностью его разрешения в трансдисциплинарной перспективе, а их сочетание, вслед за Ю. Хабермасом, автор видит, как возможность «восстановить утраченное единство разума» (Л. Киященко [1, с. 114]).

Наконец, для шестых (хотя почти у каждого автора можно найти вариации - но это именно вариации, тогда как мы обращаем внимание на индивидуальную трактовку или предлагаемый учёными номинативный ряд понятий, представлений) Т. становится прямым следствием этимологической «операции», в силу которой речь идёт об исследованиях, которые «идут через, сквозь границы многих дисциплин, выходят за пределы конкретных дисциплин» (Е. Князева [1, с. 283]). Важное для названного автора представление о «теории сложности» (с. 286 - здесь мы не можем не вспомнить публикации по проблемам синергетики авторов настоящей монографии Е. Князевой, Л. Киященко и некоторых других) коррелирует у Е. Князевой не только с Т., но и с понятиями «полидисциплинарность» и «кооперация» [1, с. 282], а у Я. Свирского - не только с утвердившимися в синергетике «точками бифуркации», но и с имеющими социальнофилософские семантические привязки «текстом» и «контекстом» [1, с. 250-251].

Отметим попутно, что вариации с частицей «транс-» присутствуют как в русскоязычных, так и в англоязычных текстах (Дж.Т. Клейн [1, с. 81]), когда возникают и «трансгрессия», по М. Фуко, как направленный на разрушение границ жест, и давно уже привычное «трансценденция» (которую в контексте монографии можно понимать не только как методологически детерминированную операцию, но и как способ миропонимания, а если углубляться в философско-культурную традицию, то и как присущий романтической или символистской парадигмам способ бытия).

Если не образцом, то убедительным проявлением трансдисциплинарности, в парадигме которой стремятся работать сами авторы монографии, мы полагаем тот терминологический модус, которым характеризуется ряд текстов, мягко, но уверенно резонирующих друг с другом. Не имея возможности детализировать анализ всех текстов и всех идей, обратим внимание хотя бы на состав ключевых слов, предпосылаемых каждому тексту. 


\section{Философия и культура 4(100) • 2016}

Среди ключевых слов, как и, разумеется, в «теле» текстов многократно встречаются такие значимые для обсуждения и решения проблемы Т. понятия, как «коммуникация» (А. Огурцов [1, с. 94]; Б. Пружинин [1, с. 252]; В. Буданов [1, с. 155]), «деятельность» и «действие» (М. Кеестра [1, с. 202] и др.). Особенно важным представляется внимание А. Огурцова к понятию, имплицитно присутствующему в разных текстах, употребляемому подчас едва ли не всуе, и вдруг рассмотренному специально, проведённому через текст последовательно и бережно, - «смысл». В противовес известной тенденции сужения проблемного поля этого, - нет, не понятия, но категории, - при буквальности семиотических реплик и цитирований (привычка разведения «значения» и «смысла», по Г. Фреге), учёный апеллировал к М. Хайдеггеру, выделив «смысл» как «способ разверзания бытия и экзистенции человека» (А. Огурцов [1, с. 103]).

Работа с терминологическим аппаратом - как увлекательна, так и неблагодарна. Одни термины кажутся привычными и не требующими комментариев, тогда как анализ этимологии и семантики в действительности актуален применительно к новым проблемным коллизиям. Другие термины кажутся новыми и этим прекрасными, хотя уже были апробированы в той или иной научной сфеpe, но, возможно, позабыты или мало востребованы. В тексте П. Тищенко присутствуют оба названных варианта работы с терминами. С одной стороны, приходится возразить автору работы, посвящённой «контексту языка» в отношении авторства, как он называет, неологизма «концентр» [1, c. 479]; автором этого понятия не может считаться названный таковым Вл. Луков в силу того, что оно как минимум 80 лет назад верифицировано в словаре Ушакова: «Ступень обучения, связанная с предыдущей единством содержания и отличающаяся от неё большей сложностью и объемом» [2, ст. 1454]. С другой стороны, нельзя не восхититься иронической метафоричностью научного текста в сочетании с подлинной междисциплинарностью привлечения опыта другой эпохи и другой науки; речь идёт об обращении того же П. Тищенко к гениальной проговорке В. Шкловского [1, с. 471-472] - «остранение», возникшей в параллель (о чём сегодня мало кто помнит) со знаменитой «теорией отчуждения» Б. Брехта. Среди строгого и непростого текста философа лёгкость упоминания возможности «остранить (в смысле В.Б. Шкловского)» читается как элемент интеллектуальной игры, в логику которой элегантно вписывается и собственная выразительная словесная конструкция философа - «мощь от-сут(ь)ствия» [1, с. 472].
Из многих и разных терминов, востребованных в монографии о Т., полагаю необходимым выделить термин «дискурс», то просто употребляемый, то углубленно обсуждаемый авторами текстов. Возможно, философам - авторам монографии покажется странной причина нашего особого внимания к этому, казалось бы, общеупотребимому термину, однако сошлюсь на удивительное высказывание, услышанное недавно в ходе работы руководимого мною диссертационного совета, где доктор наук-историк клеймил более молодого коллегу за использование термина «дискурс» (цитирую дословно фрагмент устного высказывания): «С моей точки зрения, такая формулировка свидетельствует о недопонимании автором диссертации самого понятия “дискурс". Эта категория была введена в историографию основателем постмодернизма М. Фуко. Это понятие пришло из постмодернизма и подразумевает систему осознанных и неосознанных правил, по которым строится говорение по той или иной теме. Дискурс - это то, что можно назвать “на кончике языка”. Например, говорящий может непроизвольно подстраиваться под те правила, которые господствуют сегодня в говорении о русской православной церкви. Исследователь может попытаться распутать клубок дискурсивных правил говорения, но он не может создавать дискурс. Это неуместное понятие». В монографии же о трансдисциплинарности чрезвычайно важным представляется уважительно-свободное обращение авторов с понятием «дискурс», когда, например, оно может быть употреблено во множественном числе (В. Буданов [1, с. 145]), а может быть включено в состав ключевых слов, в едином ряду со «смыслом», который понимается как цель, «интенция», которая читается как индивидуальное побуждение, не без упоминания о М. Фуко - куда же без этого. Причём в этом, последнем случае (А. Огурцов [1, с. 94,106]) обозначен интеллектуально значимый «узел» понятий, связанных ясно, тонко и убедительно: подчёркнуто «различение смысла и значения, внутрисмысловых интенций», что способствовало появлению того, «что сейчас называется дискурс-анализом» (А. Огурцов [1, с. 107]).

«Дискурс» выглядит в монографии понятием значимым, явлением широким и осмысленным. Он воспринимается едва ли не как живое существо, ибо можно обсуждать его «поведение» - он то «заходит на чужую территорию», то «начинает осваивать предметности», дискурсы могут встречаться на спорной территории, у дискурса могут быть границы, впрочем, иногда нечёткие (Г. Гутнер [1, c. 269, 263]). Более того, в монографии буквально 
на одной странице встречаются друг с другом два главных и кровных «врага», обнаруживаемых некоторыми гуманитариями в междисциплинарной научной терминологии, два понятия, раздражение против которых высказывалось и подчас высказывается сейчас стремящимися к «традиционной прозрачности» и «чистоте речи» представителями таких дисциплин, как искусствоведение, история, филология. Эти «враги» - уже упомянутый «дискурс» и связанная с ним «парадигма». И вот, прежде чем сказать вполне очевидное и едва ли уже не бесспорное в контексте смыслов монографии «научная дисциплина также является дискурсом», автор предлагает афористичное, тонкое и, с нашей точки зрения, убедительное, полезное даже для начинающих исследователей - студентов или аспирантов - определение: «Дискурс есть своего рода парадигма, задающая образцы построения речей и текстов» (Г. Гутнер [1, с. 267]).

Термины, понятия и концепты, обсуждаемые в монографии, можно сказать, работают на смысл представления о трансдисциплинарности, помогая уточнять, расширять и трансформировать его, в меру необходимости.

\section{3. Трансдисциплинарность в аспекте фундаментального и прикладного}

Авторы монографии, как и все философы мира, живут в уверенности: «фундаментальное» и «прикладное» составляют дихотомию, преодоление которой осуществляется трудно, если вообще осуществляется. И если существование трансдисциплинарности становится основанием фактической реабилитации самого факта существования «прикладного», то это - великое чудо, поскольку в недрах последнего «нарабатывается сегодня новое знание» (Б. Пружинин [1, с. 258]). Философы чувствуют флюиды современности и понимают необходимость неконфликтного существования «высокой» науки и «низкой» практики, говоря о необходимости осуществить «трансцентирующий сдвиг в пограничную сферу с жизненным миром» (Л. Киященко [1, с. 116]).

Разводя уже на уровне состава ключевых слов своего текста понятия «фундаментальная наука» и «прикладное исследование» - т.е., подчёркивая разномасштабность фундаментального и прикладно2о, - Б. Пружинин [1, с. 254] не только акцентирует трансдисциплинарность как основу существования того и другого дискурсов, но касается важнейшей в современных гуманитарных практиках, но по сути своей не изученной и даже не артикулированной всерьёз сферы, где необходима трансдис- циплинарность: речь идёт об экспертизе как прикладной деятельности в сфере фундаментальных наук. Пусть вскользь, но упоминается даже значимость «личного общения учёных», которая имплицитно присутствует в той самой экспертизе. Те, кому приходится осуществлять экспертную работу, будь то изучение заявок, поступающих в научные фонды или деятельность в диссертационных советах, знают, сколь значима упомянутая проблема и сколь многие нити связывают науки и людей в экспертной сфере. Наша экспертная работа, как позволяет предположить Б. Пружинин, а предположив, согласиться с ним, протекает не только в трансдисциплинарной сфере [1, с. 260], но, скажем так, в трансграничной, а то и безграничной (что бывает связано в нечёткостью позиций или самонадеянностью авторов экспертируемых работ). Экспертное сообщество занимает представления и другого автора, В. Буданова [1, с. 157], который вольно и решительно включает в единый номинативный ряд с экспертным сообществом и телевизионную игру, и деятельность научных школ, от чего философское представление о современной антропосфере становится объёмным, странным и «живым». Добавив, к упомянутым прагматически детерминированным аспектам предмета трансдисциплинарной мысли ещё и научно-образовательный пафос, отчётливо присутствующий у В. Бажанова $[1$, с. 144$]$, читатель монографии получает важный импульс понимания круга интересов современных философов: это интересы не абстрактные, учитывающие живое движение общественной и научной жизни. Отсюда - такая редкая особенность философской монографии, как многообразие присутствия в ней иных, кроме традиционно и сугубо философских, мотивов и проблем. Речь идёт о том, что целая группа текстов углубляется в те сферы, изучение которых в трансдисциплинарной парадигме является новым и особенно значимым.

Посетуем, напомнив сказанное нами в начале этого текста: среди сфер, которые назовём ниже, отсутствует культура как системная целостность или отдельные её морфологические составляющие. Она, культура, лишь изредка и вполне случайно упоминается, но не привлекает специального интереса. Тем важнее для нас учесть опыт трансдисциплинарности, приобретённый в связи с другими сферами, и экстраполировать его в сферу культуры, для которой трансдисциплинарность - насущна и необходима, но, с точки зрения многих опытным и в той или иной степени влиятельных исследователей, не применима или применима в ограниченном формате. Для нас же 


\section{Философия и культура 4(100) • 2016}

значимость трансдисциплинарности как оформившегося философского дискурса культуры несомненна, поэтому мы и обращаем внимание на то, как авторы монографии работают с иными, близкими им сферами.

Мы для себя следующим образом обозначили круг тех научных проблем и сфер действительности, к которым авторы монографии попытались применить имевшиеся в их распоряжении принципы трансдисциплинарности. Прежде всего, это две группы проблем, которые в широком смысле можно назвать общественными, или социогуманитарными, с одной стороны, и естественнонаучными, с другой. Впрочем, названное деление учитывает лишь доминанты, поскольку общественная значимость естественнонаучной проблематики также учитывается авторами монографии.

В первой группе, условно обозначенной нами в связи с общественной проблематикой, мы видим концептуальный обзор вызовов «в проблематике управления», предложенный В. Лепским [1, с. 543544]. Автор выходит и на субъектность управления, и на глобальный, научно-дисциплинарный уровень. Хотя представляется странным, что проблематика управления именно в её субъектности не была соотнесена с социально-психологическим потенциалом теории лидерства в его остром значении для политики, экономики, кстати, и культуры. Хотя, поскольку автор начинает разговор об управлении с позиции, названной «классическое кибернетическое управление» [1, с. 547], понятно, что личностный фактор не находится в числе его научных приоритетов, а ведь лидер - это как бы то ни было личность. Из контекста же понятно в аспекте традиций постнеклассической философии, что «субъект», который терминологически востребован в тексте, не является синонимом «личности», он лишь задействован в связи с парадигмой «субъект - полисубъектная среда в управлении экономическими системами» (В. Лепский [1, с. 555]). Но даже вопрос или недоумение, рождаемое текстом монографии, мы рассматриваем как продуктивный путь к продолжению диалога.

К общественной же проблематике можно отнести тексты Ю.Ищенко, где сделана попытка подойти к толерантности с позиций трансдисциплинарности [1, с. 306, 308]; И. Асеевой, у которой востребована проблематика «прогностического опыта» и обозначена надежда на построение модели «возможного будущего» [1, с. 529, 537]; Вл. Лукова, обозначившего потенциал трансдисциплинарности применительно к стремлению «расширить границы исследования» ювенологического проблемного поля [1, с. 488-489].
Во второй же группе, условно обозначенной нами в связи с естественнонаучной проблематикой, особое внимание обращает на себя рассуждение В. Горохова о необходимости и, скажем так, неотвратимости «трансдисциплинарности в силу того, что одна часть научного сообщества по отношению к другой выступает в качестве профанов, мало отличающихся от обычной публики» $[1$, c. 510], и это говорится сегодня, когда количество кандидатских и даже докторских диссертаций, защищаемых ежегодно, измеряется не сотнями, а тысячами! Мы же в этом суждении, приведённом в тексте с нанотехнологической и, шире, физической проблематикой, видим важный в психологическом отношении акцент, о котором одни стесняются говорить, а другие высокомерно и подчас бестактно подчёркивают. В то же время философ, который пишет о существовании «нанотехнологических рисков» [1, с. 516], даёт пример не только свободного, но и в своём роде самокритичного поведения в мире узкоспециального знания и абсолютизации не просто научной, но знаниевой исключительности. В том же, естественнонаучном проблемном ряду мы видим некоторые рассуждения В. Бажанова, предлагающего анализ такого конкретного феномена, как «пан-компьютеризм» [1, с. 142], а также ряд материалов, посвящённых разным аспектам проблемы биоэтики. В версии Л. Киященко [1, с. 112-113] и П. Тищенко [1, с. 474] это связано с методологией биоэтики, тогда как с анализом конкретных аспектов и коллизий - в версии Т. Сидоровой (о суррогатном материнстве [1, с. 357]), Е. Гребенщиковой (о влиянии пациентов на принятие решений в сфере взаимодействия медицины, социума, бизнеса [1, c. 506]), Б. Юдина (о «сфере этической экспертизы биомедицинских исследований» [1, с. 320]).

\section{Диалог (или его попытку) приходится завершать}

Мы не будем давать развёрнутое резюме, подводящее итог рассуждениям, к которым подвигла монография российских философов и их зарубежных коллег. Отметим, среди многих ранее выделенных идей и позиций, сомнений и приятий, реплику Б. Пружинина о реальности и значимости «междисциплинарных» и «наддисциплинарных» контактов, в роли которых выступает обсуждаемое в монографии представление о трансдисциплинарности. В интересах развития молодой науки, культурологии, мы видим обращение к опыту древнейшей науки, философии, - возможность работать в логике, согласно которой «прикладному знанию вновь возвращается культурное достоинство» [1, 
c. 252]. Наверное, это имели в виду и хотели обозначить как важное для будущих единомышленников в продвижении трансдисциплинарности авторы монографии, используя в эпиграфах эпические слова И. Бродского о пространстве, которое «нуждается сильно во взгляде со стороны» и Н. Заболоцкого - слова печальные и обнадеживающие: «Как всё меняется!».

\section{Список литературы:}

1. Трансдисциплинарность в философии и науке: подходы, проблемы, перспективы / Под ред. В.А. Бажанова, Р.В. Шольца. М.: Изд. дом «Навигатор», 2015. 564 с.

2. Толковый словарь русского языка / Под ред. проф. Д.Н. Ушакова. М.: ОГИЗ, 1935. Т. 1. 1566 столбцов.

\section{References (transliterated):}

1. Transdistsiplinarnost' v filosofii i nauke: podkhody, problemy, perspektivy / Pod red. V.A. Bazhanova, R.V. Shol'tsa. M.: Izd. dom «Navigator», 2015. $564 \mathrm{~s}$.

2. Tolkovyi slovar' russkogo yazyka / Pod red. prof. D.N. Ushakova. M.: OGIZ, 1935. T. 1. 1566 stolbtsov. 